\title{
Topic Maps as Indexing Tools in the Educational Sphere: Theoretical Foundations, Review of Empirical Research and Future Challenges
}

\author{
Vivek Venkatesh, Kamran Shaikh and Amna Zuberi \\ Concordia University \\ Canada
}

\section{Introduction}

Topic Maps (International Organization of Standardization [ISO 13250], 1999; 2002) are a form of indexing that describe the relationships between concepts within a domain of knowledge and link these concepts to descriptive resources. Topic maps are malleable - the concept and relationship creation process is dynamic and user-driven. In addition, topic maps are scalable and can hence be conjoined and merged. Perhaps, most impressively, topic maps provide a distinct separation between resources and concepts, thereby facilitating migration of the data models therein (Garshol, 2004).

Topic map technologies are extensively employed to navigate databases of information in the fields of medicine, military, and corporations. Many of these proprietary topic maps are machine-generated through the use of context-specific algorithms which read a corpus of text, and automatically produce a set of topics along with the relationships among them. However, there has been little, if any, research on how to use cognitive notions of mental models, knowledge representation and decision-making processes employed in problemsolving situations as a basis for the design of ontologies for topic maps.

This chapter will first outline the theoretical foundations in educational psychology and cognitive information retrieval that should underlie the development of ontologies that describe topic maps. The conjectural analyses presented will reveal how various modes of online interaction between key stakeholders (e.g., instructors, learners, content and graphical user interfaces), as well as the classic information processing model, mental models and related research on problem representation must be integrated into our current understanding of how the design of topic maps can better reflect the relationships between concepts in any given domain. Next, the chapter outlines a selective review of empirical research conducted on the use of topic maps in educational contexts, with a focus on learner perceptions and cognitions. Finally, the chapter provides comments on what the future holds for researchers who are committed to the development, implementation, and evaluation of topic map indexes in educational contexts.

Source: Cognitive Maps, Book edited by: Karl Perusich,

ISBN 978-953-307-044-5, pp. 140, January 2010, INTECH, Croatia, downloaded from SCIYO.COM 


\section{Topic maps: A primer}

Topic maps separate the inter-related topics in a given body of knowledge from the actual resources that describe these topics. They provide context-based searches that can match context-specific search criteria entered by the user (Pepper, 2002; Garshol, 2004). As a search-and-retrieval technology, topic maps provide a method to code content in terms of topics, the relationships between these topics, and any additional informational resources associated with the target subject matter. This allows for greater flexibility in searching because the user not only gains access to information directly associated with a topic but also gets information regarding related topics. Results are returned not by keyword "hits" but rather by the concepts or ideas present in a corpus. A search will return fewer, more relevant "hits" matching the key word with the appropriate semantic context (Rath, 2000). Given their capability, topic maps can support learning within an online learning environment (OLE) in that content across functions can be integrated through search functionality triggered by a learner's query. Topic maps can help to provide the learner with a uniquely individualized tool that customizes how content is accessed and potentially organized.

Pepper (2002) refers to the elements of a topic map using the acronym TAO - Topics, Associations, and Occurrences. Let us consider a simple example of a topic map created to describe the body of knowledge related to e-learning. Topics pertinent to the subject matter of e-learning could include, for example, software platforms, learning management systems, learning content management systems, learning objects, industry standards, and interoperability, among others. Associations draw out the relationships between topics. For example, consider the following statement where the underlined portion details an association linking the topic "Interoperability Standards" to the topic "Metadata Schemes": "Interoperability standards are used in evaluating Metadata Schemes"; note also that this association is bi-directional, and hence, logically leads to the following statement: "Metadata Schemes are evaluated by Interoperability Standards". Occurrences point the user to resources that provide information about the topics themselves. An occurrence dedicated to the topic "Metadata Schemes" could be a pointer to an online article comparing the various metadata standards used in the industry. Topic maps also allow multiple naming conventions, which allow topics to be described in a variety of languages or by different titles according to user preference. Topic maps permit the assignment of metadata to information resources, similar to resources that possess XML tagging. Topics within a topic map can also be assigned a scope within which they are considered valid, thereby avoiding problems arising from the use of a topic in multiple contexts.

Arguably, the quality of the search results obtained through using a topic map depends largely on the topic map developer's ability to extract stakeholders' representations of the domain of knowledge being mapped. Proponents of the cognitive information processing (CIP) theory, proposed by Waugh and Norman (1965) and Atkinson and Shiffrin (1968), have explored the role of representations of ill-structured problems (Reitman, 1965) in various contexts (Voss, 1998; Voss \& Post, 1988). Research has also shown that differences in problem solving ability between novices and experts can be partially attributed to their different problem representations (e.g., Voss et al., 1998; Torney-Purta, 1992). Taking this research into account, our development of topic maps is grounded in one or more expert's cognitive representations of the domain, and an analysis of the tasks to be performed by end-users who will be navigating the domain using the topic map. 
Taxonomies, as a classification scheme or hierarchy of terms for cataloguing content can form the basis of a system for managing large, complex collections of information. While taxonomies and ontologies are terms that are used interchangeably, ontologies tend to include instantiations, constraints, and an extra element of theory - a notion that the structure actually describes reality, not just a method of organizing data (Kabel, deHoog, Wielinga \& Anjewierden, 2004). As such, ontologies perhaps come closer to mental models of intellectual content. McGuiness (2001) contends that ontologies must exhibit certain required properties, namely, a finite controlled vocabulary, unambiguous interpretations of classes and term relationships, as well as strict hierarchical subclass relationships. In addition they may possess typical non-mandatory properties, such as value-restriction and specifications of arbitrary logical relationships between terms. Generally, these properties permit the construction of complex knowledge structures which give ontologies a significant advantage over other forms of organization. Following from our leanings toward a theory of CIP, we propose constructing a topic map for a given domain on a set of validated taxonomies and/or ontologies that emerge from an experts' view of that domain, including its topics, associations and occurrences.

\section{Theoretical foundations}

Information processing and its related theories should be instrumental in providing a framework for the design of ontologies that describe topic maps. In addition, investigating learning and its related processes in OLEs must take into account how learners regulate cognitions and metacognitions with respect to academic tasks, as well as how information retrieval is closely tied to elements of academic self-regulation. The following theoretical dissection of how specific elements of educational psychology-based literature intersect with those of the library sciences will illuminate the necessity of bridging the gap between these two seemingly disparate fields.

\subsection{Theories of self-regulated learning}

Academic self-regulation involves the strategic application and adaptation of learners' cognitive and metacognitive thought processes in influencing their own behaviour while tackling academic tasks (Pintrich, 2000; Zimmerman, 2000; Winne \& Hadwin, 1998), taking into account their emotions (McCombs \& Marzano, 1990) as well as motivational states (Pintrich, 2000; Pintrich \& De Groot, 1991; Winne \& Hadwin, 1998) within a specific learning context or environment (Winne \& Hadwin, 1998). Some models of self-regulated learning (SRL) acknowledge the need for regulating all the five elements of cognition, affect, motivation, behaviour and context in explaining individual self-regulating processes. Most models of SRL promote goal-setting, strategic planning and execution of plans, reflection, self-monitoring, self-efficacy, and self-evaluation as essential skills to be developed by learners who engage with complex tasks requiring resource management skills, individual and group analyses of problem situations, as well as strategic use of feedback and contextually available resources. A critical, but under-researched concept subsumed within the notion of SRL is task understanding, which is considered to be a frontline phase of SRL (Venkatesh, 2008; Venkatesh \& Shaikh, 2008).

Self-regulated learners apply both cognitive and metacognitive strategies, such as reflection and performance calibration, when completing academic tasks, taking into account 
contextual and task-specific conditions (Venkatesh, 2008; Venkatesh \& Shaikh, 2008; Winne \& Hadwin, 1998). While much is known about how to build self-regulatory competencies using sound instructional design principles, educational psychologists still struggle to understand and describe the interactions between the various individual components of self-regulated learning (SRL). Perhaps this is an artifact of classic conceptions of SRL as a complex, process-oriented theoretical construct; such an epistemological assumption makes it difficult to tease apart how learners think about the rationale for completing an academic task as well as how well they monitor their performance relative to the instructor's assessment criteria.

\subsection{Ontological Levels of Learner Perceptions}

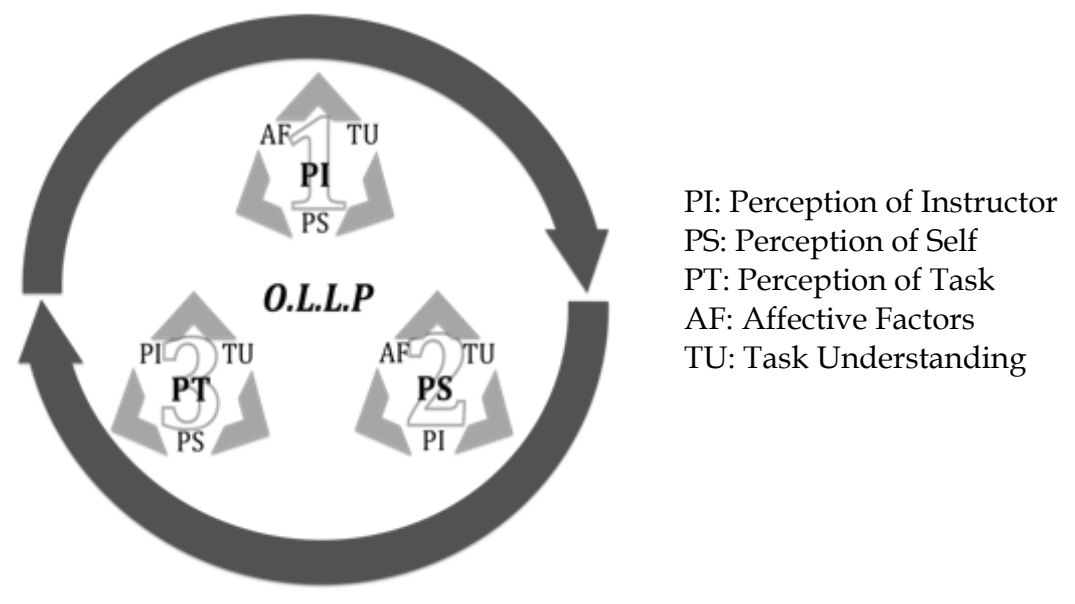

Fig. 1. Ontological levels of learner perceptions (OLLP)

To better understand the implications of theories of SRL in the cognitive realm of information retrieval and use, we pose the following question: How is task understanding developed and affected by other self-regulatory processes that learners engage with while performing academic tasks? In proposing hierarchical and ontological levels of learner perceptions of feedback (Shaikh, 2008, provides the empirical evidence upon which the model is based) we attempt to shed new light on the effect of credibility, respect, trustworthiness, status and myriad of other factors as an influence on how students interpret feedback from certain instructors and their conception of 'self-as-learner'. When tackling a task for the first time, there is a hierarchical view to how students perceive the provider (i.e., the instructor) and the receiver (i.e., themselves) of feedback. For example, self-perceptions, such as confidence and motivational levels, take a back seat to how the provider of feedback is perceived by the learner, the student body as a whole and the educational environment. The learner bases feedback internalization on a multi-faceted system using the following hierarchical taxonomy:

- Tier 1 - Perception of Provider: Instructor must be seen as a viable source of information. If not, feedback is disregarded 
- $\quad$ Tier 2 - Self-Perceptions: Learners' perception of self-worth, esteem, confidence and ability

- $\quad$ Tier 3 - Perception of Task: Inherent worth of the task and transferability to other scenarios

Further iterations or subsequent attempts of a given task are accompanied by other connections. Temporal effects of instructor feedback on learners' self-regulation while engaging in an academic task contends that learners prioritize a triad of perceptions in an ontological scheme, viz., the instructor, self-as-learner and task. Over time and through experience in a learning environment, learners choose which of these three perceptions take precedence, thereby influencing to varying degrees, how cognitions are employed to successfully meet the criteria for completion of a task.

For example, the perception of the provider can become dependent upon context and therefore it will be demoted from top tier status. Experiential factors, such as previous interaction with instructors, peer reviews or perceived expectations, play an extensive role in how a learner perceives their interactions and proficiency within a setting and therefore reliance upon instructor support and acknowledgement may decrease. With respect to extraneous variables (for example, context, experience, understanding of task and self, ego, previous interactions and respect) a hierarchical approach may not be all encompassing and an ontological description may prove worthwhile for further investigation. The ontological levels of learner perception (Figure 1) can serve as a framework for how students and instructors monitor progress and performance on academic tasks as well as possibly characterize the nature of the feedback internalization process, especially as learners navigate resources using an intuitively designed indexing mechanism such as a topic map. Boiled to its essence, these levels of perception provide a cognitive framework to investigate temporal and perspective-dependent aspects of task understanding.

\subsection{Theories of Cognitive Information Retrieval (CIR)}

The cognitive approach to information sciences began with De Mey's (1982) theories which were centred on the interaction between the user and the intermediary (human or computer). To this theory, Ingwersen (2000) adds the notion of the cognitive structures framed by the individual user, which are dependent on collective experiences, education, training and other individual and social cognitive factors. It is important to note that the cognitive psychological view of learning (as represented by the theory of SRL) would recommend that users' perceptions, epistemological beliefs as well as value frameworks influence and are, in turn, influenced by the cognitive structures that an individual brings to the information retrieval task. Ingwersen's view on the CIR theory, therefore, already attempts to bridge the gap between psychological theories of learning and the more humancomputer interaction oriented theories of information science.

Ingwersen (2000) lays out the five major elements of the CIR theory. The first players are the information objects or knowledge sources as entities themselves, including their representations. These representations originate from the author(s) of the sources and necessarily depend on the representation(s) imposed by the indexer (human or machine) of the sources. The second set of players is the system structures, such as the retrieval algorithms, which are normally generated by the designers of an Information Retrieval (IR) system. These system structures depend on the indexer(s) of the sources as well. The third component refers to the interface functionalities of the IR system. These are created by 
system designers and may consist of cognitive structures imposed by human intermediaries in the IR process. The fourth element refers to the users' cognitive space, which consists of the perceptions about the work task and the situational perceptions surrounding the task. The cognitive space of the user also includes representations of the current state of knowledge, problem and uncertainty states. We would also venture to suggest that the CIR theory would accept that these cognitive spaces also subsume the cognitive and metacognitive strategies that the user has learnt in the past, and is able to draw upon to conduct, for example, means-ends analysis in problem-solving situations. The fifth and final piece of the CIR theory refers to the socio-organizational environments, including situational contexts, domain structures, the work tasks themselves, as well as access to strategies to solve problems.

\subsection{Intersection between self-regulated learning and cognitive information retrieval}

The description of CIR theory alludes to the concept of temporality in the IR process. This means that users of an IR system are necessarily bound by a time frame, which could provide a useful framework to understand how elements of the users' cognitive space interact with the other four elements of CIR theory. Similarly, cognitive assumptions about SRL also delineate a time-based perspective on how learners tackle academic tasks. However, in our opinion, theories of SRL fall short in focusing on what elements of task understanding one should devote attention to, in terms of measuring and promoting, in specific learning contexts. Additionally, keeping with the discussion of time frames, the issue that begs to be addressed is - at what point during an instructional event should a researcher expect to encounter changes in task understanding. Researchers of SRL have adopted a wide range of units of analyses, from individual students to timed classroom events, depending on which qualitative methodology is being used to investigate the phenomenon in question. CIR theory provides an excellent platform from which to test domain-specific theories of task understanding as a temporal phenomenon.

\subsection{Task understanding}

It remains now to uncover how task understanding is best served by viewing it under the lenses of both the theories of SRL and CIR. According to currently held theories of SRL, task understanding draws on two distinct, but interacting elements; these include individuals' perceptions of the academic task, as well as of themselves as a learner within a particular academic context. Learners' perceptions of the academic task include both the nature of the task, and the assessment criteria associated with the task. Learners reflect on their perceptions of the nature of the task, including: (a) the rationale for performing the task; (b) the procedures that need to be undertaken to perform the task and the required outputs; (c) the materials that are available to perform the task; as well as (d) the contextual conditions under which the task has to be performed. Learners also need to grapple with the assessment criteria that the instructor uses to judge their performance on the task. It is therefore clear that task understanding involves a close interaction between learners' perceptions and the instructor's perceptions of the academic task (Venkatesh \& Shaikh, in press).

In addition to the task-associated elements, task understanding is influenced by the learner's knowledge of "self-as-learner". Such knowledge includes preferred learning styles and learning needs, prior content and task-specific knowledge, current motivational and emotional levels of anxiety and efficacy, as well as motivational and emotional levels associated with a specific type of task environment. 
Ingwersen's (2000) model emphasizes a constant interaction between the cognitive space of the user and the socio-contextualized environment; these interactions influence human behavior during the IR event within the system. Moreover, dynamic interactions and interpretations change the information need and influence, in turn cognition and learning. As Ingwersen (2000, p.10) exhorts: “... it is essential to uncover the kind of cognitive factors or structures that triggers users' information needs and problem statements, for example, the reasons for users (mis)conceptions of classification structures or icons in systems. The cognitive nature of representative structures of information objects or knowledge sources are thus of interest directly". Ingwersen's conceptualization of CIR theory places great importance on elements of task understanding illuminated by current SRL theorists. According to CIR theory, the task and its perception by a user is considered just as valuable as the information need. In fact, Ingwersen also points out that the perception about the work task leads to the perceived information need. In a cognitive sense, the user's perception of a work task is more likely to be stable over the IR session time than the corresponding dynamic information need. Perception of work task is important, then, to provide the context necessary for the system to retrieve relevant information. However, initial empirical evidence reported in Venkatesh and Shaikh (2008) suggests that learners' information needs fluctuate as their task understanding improves. While these findings stand in contrast to Ingwersen's (2000) conjectures, it remains to be seen how future research formalizes the temporal aspects of task understanding in IR environments.

\section{Review of empirical research on learners' cognitions while using topic maps}

There exists a large community of practitioners and researchers who present and publish technically oriented work related to the development and implementation of topic maps (e.g., the annual Topic Map Research and Applications Conference [TMRA] in Leipzig, Germany). The purpose of our review of research is to provide an illustration of the cognitive orientation of researchers who assess learners' use of topic maps. Hence, this section will provide a selective review of empirical research conducted on the use of topic maps in educational contexts and its effects on learner cognitions.

Databases that were consulted for the purpose of this review include Association for Computing Machinery (ACM), Institute of Electrical and Electronic Engineers (IEEE), Explore, Education and Information Technology Digital Library ([EdITLib], hosted by the Association for the Advancement of Computing in Education [AACE]) as well as Education Information Resources Centre (ERIC). Searches focused on keywords of topic maps, extensible markup language topic maps (xtm) and its variations. Articles were selected based on whether they addressed educational applications of topic maps and provided evidence of learners' use of topic maps, whether from a usability or psychological standpoint. While reports of technology-related developments of topic map-based electronic learning environments (e.g., Dicheva \& Dichev, 2004; 2006) and ontology construction (e.g., Dicheva \& Dichev, 2005; Lenne, Cissé \& Abel, 2005) were captured in our searches, the lack of empirical evidence about learning processes rendered these pieces ineligible for our review. The relevant articles include those conducted by Lavik and Nordeng (2004) as part of the Brainbank project, Oh and Park (2007) who conducted an experimental comparison of a topic map-enabled retrieval system versus a hierarchical browsing system, and Shih, Shih and Chen (2007) who built and evaluated a self-organizing (SOM) topic map. Also relevant 
is the body of work by Venkatesh and his colleagues which includes an experimental comparison of university learners' use of topic maps versus their use of search engines while completing academic tasks (Venkatesh et al., 2007), a mixed-method investigation of improvements in academic performance and self-regulatory mechanisms in graduate learners (Venkatesh, 2008) and finally, a qualitative analysis of how graduate learners' task understandings and monitoring of performance develop as they use topic maps to navigate text-based repositories while solving ill-structured writing tasks (Venkatesh \& Shaikh, 2008). While it is still too early to discern how task understanding, metacognition and other selfregulatory processes unfold in information retrieval environments, the multi-method investigations presented in this section provide rich fodder to implement topic maps in educational contexts.

\subsection{Lavik and Nordeng's Brainbank project}

In a fascinating case study, Lavik and Nordeng (2004) outline how eighth grade pupils in Norway use a topic map-enabled suite of tools called Brainbank Learning (BBL) to enable cross-disciplinary learning. Lavik and Nordeng contend that through the use of the associative features of topic maps, the subjects taught to these eighth graders can be linked across the curriculum to develop competencies that span the contents (e.g., mathematics, physical/natural/social sciences, etc.). Lavik and Nordeng report on how learners become more aware of their learning processes and how these learners developed motivations to continue working with the BBL suite. In fact, the results point to learners improving their self-regulatory mechanisms, becoming more metacognitively cognizant of how to interact with the information retrieval systems they were engaging over the course of their study. Further research must be accomplished from a longitudinal standpoint to observe evidence of learning-based outcomes for technological advancements such as the BBL suite.

\subsection{Oh and Park's experimental comparison of topic maps versus hierarchical organizers}

In an experimental study, Oh and Park (2007) report on 20 learners' experiences in using topic map technologies versus an existing hierarchical classification system on a series of information retrieval tasks, ranging from simple to complex associative and crossreferencing tasks. Results of a counter-balanced experimental design revealed that learners using the topic map generally showed improved measures of completeness, ease of use, efficiency, appropriateness and satisfaction on tasks that were complex (associative and/or cross-referencing), but not on tasks that were simple or generated by the learners' own queries. However, the data do not reveal any information about the extent to which the topic map influenced learner cognitions.

\subsection{Shih, Shih and Chen's investigation of self-organizing topic map}

Shih, Shih and Chen (2007) present the results of a usability and instructional evaluation of a self-organizing topic map which indexed the content related to Chinese herbal medications. Data was collected in the form of surveys to 126 undergraduate learners enrolled in a course on Chinese herbs, as well as follow-up focus groups with a theoretical sample of learners. In general, data from the survey revealed that learners had positive perceptions towards the functional utility of the topic map. However, no data was collected with respect to cognitions or evidence of learning. 


\subsection{Venkatesh and Colleagues' implementations on topic maps in higher education}

Following from the proposed theoretical bridge between academic self-regulation and cognitive information retrieval, Venkatesh and his colleagues have published a series of studies on the application of topic maps in a higher education context. First, Venkatesh et al. (2007) demonstrated improved performance on an ill-structured writing task for 18 learners in a topic map condition as opposed to 16 others in a keyword search condition. In a separate study, Venkatesh (2008) explored the development of task understanding in 38 graduate learners using topic maps to help complete an essay-writing assignment. A mixedmethod procedure, which included multivariate repeated measures as well as inductive content analysis, yielded evidence of not only performance improvement, but also better task understanding. In a follow-up investigation, Venkatesh and Shaikh (2008), have conducted an in-depth qualitative analysis on 12 of these 38 learners, and uncovered how individual elements of task understanding, namely, perceptions for the rationale for completing the task, self-perceptions, and perceptions about the instructor engage in a tugof-war while aiding learners to traverse the topic map with the objective of writing their essays.

\section{Educational significance}

Keeping the above theoretical discussions and review of empirical evidence regarding the conceptualization of learner cognitions in IR contexts, our goal now remains to provide synopses focusing on the significance of the educational implications and applications of topic maps. Within educational realms, the map itself can be considered a beneficial learning resource which supports learner concept acquisition regarding the classification and organization of a particular domain, the connections/relationships amongst concepts, the usefulness of the domain-based information and supporting terminology. Once created, completed and validated by subject matter experts, a topic map has the potential to provide learners with a domain-centric model, specifically a visual representation.

When users begin to browse a topic map, they can view resources that are linked to concepts that have inherent semantic relationships. One of the primary differences between conventional searches and topic map searches is that users can navigate a complex web of relationships. That being said, users can stumble upon relevant information which they may not have encountered using full-text or keyword searches. Topic maps, when integrated within the context of an OLE, can therefore provide the possibility for contextualized, discovery-based experiences for learners (Shaw \& Venkatesh, 2005).

Topic maps have the ability to offer solutions to the ever-growing problem of using multiple or different terms and languages to describe a single over-arching concept. In content management and information science circles, the issues which arise from attempts to constrain users to describe content using a limited set of terms and to use these terms effectively and consistently are well known. One advantage of using topic map technology is that users and/or user groups can introduce and share their preferred terminology, keywords and labels for a particular subject. With appropriately designed topic map development tools, learners who are accessing courses in an OLE potentially can generate and use their own topic maps to help them navigate the information contained in the courses. Learners who are accessing courses in an OLE and are using appropriately designed topic map development tools will have the opportunity to conceptualize, generate and then use their self-generated topic maps that can help them navigate information and 
knowledge contained in the courses. The merging facility provided through topic maps allows learners to view similar content through multiple perspectives. Topic maps, being extensible, offer greater ease when compared with traditional approaches of integrating new insights. For example, in seasoned approaches new content classification requires that new meta-data fields be defined and populated, or consensus upon new keywords and their applications. Given the large body of research on potential automation of indexing and keyword extraction through the use of, for example, machine translation and natural language processing (where more research has been done), it would be assumed that its implementation within topic-map based environments is feasible, however they have been limited in their success. Topic maps operate at a level or levels of abstraction above regular meta-data, therefore, they may offer sophisticated means to develop indices that do not necessarily require that each resource be manually indexed. The simplification of updating and extending the relationships seen in topic maps, without the need to alter the information resources themselves, eases administration of courses in OLEs. When course material in topic map based OLEs is updated, existing topics and associations can be freely edited and new topics can be added to the existing ontological structure.

\subsection{Practical implications}

While it has been established in cognitive psychological terms that learners' task understandings are a crucial component of academic self-regulatory activities, the review of research offers specific suggestions on how individual components of task understanding can be ameliorated while learners are tackling ill-structured writing tasks using online repositories of information. We recommend using topic maps to provide opportunities for learners to view assessment criteria through multiple perspectives and various interactions (e.g., learner-learner, learner-instructor, learner-content).

Learners should be allowed to control their navigation in these online repositories by harnessing the associative powers of indexing technologies like topic maps. Individual preferences, such as browsing by subject, author, essay or grade could be better facilitated by allowing users to create their own topic-centric associations, thereby personalizing their route through the complex webs of information in online repositories. Note, however, that Venkatesh et al. (2007) have warned that user-generated indexes must undergo strict content validation, without which the domains represented by technologies such as topic maps are rendered useless due to the specious nature of the content therein.

Finally, how context and/or learner dependent is information need? We can partially answer this question by taking the easy route and pointing to individual differences and preferences. However, that would belie the complex dance that task understanding and information need engage in when learners' cognitions are commissioned in the context of online retrieval of information. While we are aware that information needs morph as the process of improvement of task understanding is undertaken by learners, future research should explore specific conditions which might govern how, when and why these needs must react to changes in learners' cognitions.

\section{References}

Atkinson, R., \& Shiffrin, R. (1968). Human memory: A proposed system and its control processes. In K. Spence and J. Spence, eds., The Psychology of Learning and 
Motivation: Advances in Research and Theory - Volume 2, New York, NY: Academic Press, p. 90-197.

De Mey, M. (1982). The cognitive paradigm: An integrated understanding of scientific development. Dordrecht, The Netherlands: D. Reidel Publishing Company.

Dicheva, D., \& Dichev, C. (2004). A framework for concept-based digital course libraries. Journal of Interactive Learning Research, 15 (4), p. 347-364.

Dicheva, D., \& Dichev, C. (2005). Authoring educational topic maps: Can we make it easier? In, Proceedings of the 5th IEEE International Conference on Advanced Learning Technologies (ICALT) 2005 (pp. 216-218). Kaohsiung, Taiwan: ICALT.

Dichev, C., \& Dicheva, D. (2006). TM4L: Creating and browsing educational topic maps. British Journal of Educational Technology, 37 (3), 391-404.

Ingwersen, P. (2000). Cognitive Information Retrieval. In M. Williams, ed. Annual Review of Information Science and Technology, Volume 34, 1999-2000. Medford, NJ: Information Today, Inc. p. 3 -52.

International Organization of Standardization. (1999). ISO 13250 Topic Maps - First Edition [Online]. Available at : http://www.y12.doe.gov/sgml/sc34/document/0129.pdf

International Organization of Standardization. (2002). ISO 13250 Topic Maps - Second Edition [Online]. Available at: http://www.y12.doe.gov/sgml/sc34/document/ 0322_files/iso13250-2nd-ed-v2.pdf

Kabel, S., de Hoog, R., Wielinga, R., \& Anjewierden, A. (2004). The added value of task and ontology-based markup for information retrieval. Journal of the American Society for Information Science and Technology, 55 (4), 348-382.

Lavik, S. \& Nordeng, T. W. (2004). Brainbank learning-building topic maps-based eportfolios. In Proceedings of First International Conference on Concept Mapping, Pamplona, Spain, (pp. 401-408). Navarra, Spain: Universidad Pública de Navarra.

Lenne, D., Cissé, O. \& Abel, M. (2002). e-Learning and Knowledge Management: the MEMORAE project. In G. Richards (Ed.), Proceedings of World Conference on ELearning in Corporate, Government, Healthcare, and Higher Education 2002 (pp. 61-66). Chesapeake, VA: AACE. Available at: http://www.editlib.org/p/8918.

McCombs, B. L., \& Marzano, R. J. (1990). Putting the self in self-regulated learning: The self as an agent in integrating will and skill. Educational Psychologist, 25, 51-69.

McGuinness, D.L. (2001). Ontologies Come of Age. In Fensel, D., Hendler, J., Lieberman, H. \& Wahlster, W. (eds.), Spinning the Semantic Web: Bringing the World Wide Web to Its Full Potential. Cambridge, MA: MIT Press.

Garshol, L. M. (2004). Metadata? Thesauri? Taxonomies? Topic Maps! Making sense of it all. Journal of Information Science 30 (4), 378-391.

Oh, S. G. \& Park, O. N. (2007). Design and users' evaluation of a topic maps-based Korean Folk Music Retrieval System. In L. Maicher, A. Sigel and L. M. Garshol (Eds.), Topic Maps Research and Applications 2006, pp. 74-89. Berlin: Springer-Verlag.

Pepper, S. (2002). The TAO of Topic Maps [Online]. Available http://www.ontopia.net/ topicmaps/materials/tao.html

Pintrich, P. R. (2000). The role of goal orientation in self-regulated learning. In M. Boekaerts, P. R. Pintrich, \& M. Zeidner (Eds.), Handbook of self-regulation (pp. 451-502). San Diego, CA: Academic Press.

Pintrich, P. R., \& De Groot, E. V. (1991). Motivational and self-regulated learning components of classroom academic performance. Journal of Educational Psychology, $82,33-40$. 
Rath, H. H. (2000). Topic maps: Templates, topology, and type hierarchies. Markup Languages: Theory \& Practice, 2 (1), 45-64.

Reitman, W. (1965). Cognition and thought. New York, NY: John Wiley.

Shaikh, K. (2008). Exploring the existence of motivational and cognitive variables affecting the perspectives and internalization of instructor-given feedback. Unpublished thesis in the Department of Education, Concordia University. Montreal, Canada.

Shih, B. -J., Shih, J. -L., \& Chen, R.-L. (2007). Organizing learning materials through hierarchical topic maps: an illustration through Chinese herb medication. Journal of Computer Assisted Learning, 23, 477-490.

Shaw, S., \& Venkatesh, V. (2005). The missing link to enhanced course management systems: Adopting learning content management systems in the educational sphere. In P. McGee, C. Carmean and A. Jafari, eds. Course Management Systems for Learning: Beyond Accidental Pedagogy. Hershey, PA: Idea. p. 206-231

Torney-Purta, J. (1992). Cognitive representations of the political system in adolescents: The continuum from pre-novice to expert. In H. Haste and J. Torney-Purta, eds. The Development of Political Understanding: A New Perspective. San Francisco, CA: JoseyBass. p. 11-25.

Venkatesh, V. (2008). Topic maps as indexing tools in e-learning: Bridging theoretical and practical gaps between information retrieval and educational psychology. International Journal of Advanced Media and Communication, 2 (3). 221-235.

Venkatesh, V., \& Shaikh, K. (2008). Investigating task understanding in online repositories equipped with topic map indexes: Implications for improving self-regulatory processes in graduate learners. International Journal of Technologies in Higher Education, 5(3), 22-35

Venkatesh, V., Shaw, S., Dicks, D., Lowerison, G., Zhang, D., \& Sanjakdar, R. (2007). Topic Maps: Adopting user-centred indexing technologies in course management systems. Journal of Interactive Learning Research, 14 (3). p. 429-450.

Voss, J. (1998). On the representation of problems: An information-processing approach to foreign policy decision making. In D. Sylvan and J. Voss, eds. Problem Representation in Foreign Policy Decision Making. Cambridge, UK: Cambridge University Press. p. $8-26$.

Voss, J. F., \& Post, T. A. (1988). On the solving of ill-structured problems. In M. T. H. Chi, R. Glaser, \& M. J. Farr (Eds.), The Nature of Expertise (pp. 261-285). Hillsdale, NJ: Lawrence Erlbaum.

Voss, J. F., Wiley, J., Kennet, J., Schooler, T. E., \& Silfies, L. N. (1998). Representations of the Gulf crisis as derived from the U. S. Senate debate. In D. A. Sylvan \& J. F. Voss, Problem Representation in Foreign Policy Decision Making (pp. 279-302). Cambridge, UK: Cambridge University Press.

Waugh, N., \& Norman, D. (1965). Primary memory, Psychological Review, 72, p. 89-104.

Winne, P. H., \& Hadwin, A. F. (1998). Studying as self-regulated learning. In D. J. Hacker, J. Dunlosky, \& A. C. Graesser (Eds.), Metacognition in educational theory and practice (pp. 277-304). Malwah, NJ: Erlbaum.

Zimmerman, B. J. (2000). Attaining self-regulation: A social cognitive perspective. In M. Boekaerts, P. R. Pintrich, \& M. Zeidner (Eds.), Handbook of self-regulation (pp. 13-39). San Diego, CA: Academic Press. 


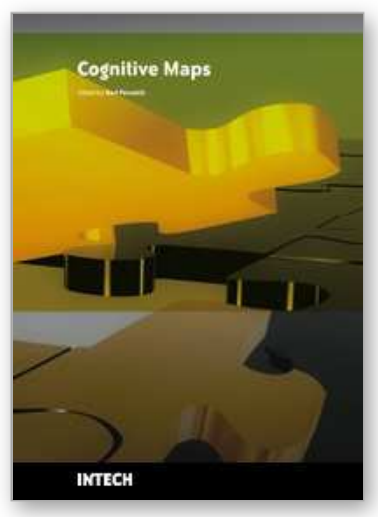

\author{
Cognitive Maps \\ Edited by Karl Perusich
}

ISBN 978-953-307-044-5

Hard cover, 140 pages

Publisher InTech

Published online 01, January, 2010

Published in print edition January, 2010

\title{
How to reference
}

In order to correctly reference this scholarly work, feel free to copy and paste the following:

Vivek Venkatesh, Kamran Shaikh and Amna Zuberi (2010). Topic Maps as Indexing Tools in the Educational Sphere: Theoretical Foundations, Review of Empirical Research and Future Challenges, Cognitive Maps, Karl Perusich (Ed.), ISBN: 978-953-307-044-5, InTech, Available from: http://www.intechopen.com/books/cognitivemaps/topic-maps-as-indexing-tools-in-the-educational-sphere-theoretical-foundations-review-of-empirical-r

\section{INTECH}

open science | open minds

\section{InTech Europe}

University Campus STeP Ri Slavka Krautzeka 83/A 51000 Rijeka, Croatia Phone: +385 (51) 770447 Fax: +385 (51) 686166 www.intechopen.com

\section{InTech China}

Unit 405, Office Block, Hotel Equatorial Shanghai No.65, Yan An Road (West), Shanghai, 200040, China 中国上海市延安西路65号上海国际贵都大饭店办公楼405单元 Phone: +86-21-62489820

Fax: +86-21-62489821 
(C) 2010 The Author(s). Licensee IntechOpen. This chapter is distributed under the terms of the Creative Commons Attribution-NonCommercialShareAlike-3.0 License, which permits use, distribution and reproduction for non-commercial purposes, provided the original is properly cited and derivative works building on this content are distributed under the same license. 